\title{
Gambaran Self Directed Learning Readiness Mahasiswa Program Studi Kedokteran Fakultas Kedokteran Universitas Andalas
}

\author{
Edwido Leonori Saputra ${ }^{1}$, Dian pertiwi ${ }^{2}$, Yose Ramda Ilhami ${ }^{3}$ \\ ${ }^{1}$ Program Studi Kedokteran Fakultas Kedokteran Universitas Andalas, Padang \\ ${ }^{2}$ Bagian Patologi Klinik Fakultas Kedokteran Universitas Andalas, Padang \\ ${ }^{3}$ Bagian Fisiologi Fakultas Kedokteran Universitas Andalas, Padang
}

\author{
A B S T R A C T
}

\begin{abstract}
Latar Belakang. Metode belajar student centered learning telah digunakan dan diaplikasikan oleh Fakultas Kedokteran Universitas Andalas sejak tahun 2004. Untuk mengikuti pembelajaran dengan metode $\mathrm{SCL}$ ini mahasiswa perlu memiliki self directed learning readiness.
\end{abstract}

Objektif. Penelitian ini bertujuan untuk melihat bagaimana self directed learning readiness mahasiswa Fakultas Kedokteran Universitas Andalas.

Metode. Penelitian ini merupakan penelitian deskriptif dengan pendekatan Cross sectional. Sampel penelitian ini adalah mahasiswa program studi kedokteran FK Unand, menggunakan metode stratified random sampling didapatkan sampel tiap angkatan 2016, 2017, 2018, 2019 secara berurutan adalah 72, $75,80,74$ mahasiswa. Pengambilan data penelitian ini menggunakan kuesioner SDLRS yang diadaptasi oleh Zulharman et al. Data penelitian dianalisa menggunakan analisis univariat.

Hasil. Mahasiswa program studi kedokteran Fakultas Kedokteran Universitas Andalas tergolong memiliki kesiapan belajar mandiri tinggi karena sebanyak $213(70,8 \%)$ mahasiswa memiliki skor SDLR tinggi dan sebanyak $88(29,2 \%)$ mahasiswa memiliki skor SDLR sedang-rendah. Rata-rata skor SDLR tertinggi dimiliki oleh angkatan 2016 yang motivasi dan kontrol dirinya juga tinggi. rata-rata skor SDLR terendah dimiliki oleh angkatan 2017 yang manajemen diri dan kontrol dirinya juga rendah, sedangkan untuk 2018 memiliki manajemen diri yang baik tetapi rendah dalam motivasi belajar.

Kesimpulan. self directed learning readiness mahasiswa program studi kedokteran Fakultas Kedokteran Universitas Andalas berada dalam kategori baik.

Kata kunci : student centered learning, self directed learning readiness, SDLRS

Background. Student centered learning system has been used and applied by the Medical faculty of Andalas University since 2004To learn with this SCL method students need to have selfdirected learning readiness.

Objective. This reaserch aims to describe the Medical student self directed learning readiness in Medical faculty of Andalas University.

Method. This research is a descriptive study with a cross sectional approach. The sample of this research was Medical student at FK Unand, using the stratified random sampling method obtained samples of each class 2016, 2017, 2018, 2019 were 72, 75, 80, 74 students respectively. Data collection in this study used the SDLRS questionnaire which was adapted by Zulharman et al. The research data were analyzed using univariate analysis.

Results. Medical student self directed learning readiness in Medical faculty of Andalas University were classified as having high self directed learning readiness because as many as 213 (70.8\%) students had high SDLR scores and as many as 88 (29.2\%) students had medium-low SDLR scores. The highest average SDLR score is owned by the 2016 class whose motivation and control are also high. the lowest SDLR average score is owned by the 2017 class whose self management and self control are also low, while in 2018 they have good selfmanagement but are low in learning motivation.

Conclusion. Self-directed readiness of students of the Medical Study Program at the Faculty of Medicine, Andalas University is in the good category.

Keywords: student centered learning, self directed learning readiness, SDLRS

\section{Apa yang sudah diketahui tentang topik ini?}

Self directed learning readiness adalah hal yang sangat diperlukan oleh mahasiswa dalam sistem pembelajaran student centered learning.

\section{Apa yang ditambahkan pada studi ini?}

Gambaran self directed learning readiness mahasiswa program studi kedokteran Fakultas Kedokteran Universitas Andalas

\section{CORRESPONDING AUTHOR}

Phone: +6285365002152

E-mail: $\underline{\text { edwido@gmail.com }}$ 
ARTICLE INFORMATION

Received: July $22^{\text {nd }}, 2020$
Revised: May $3^{\text {rd }}, 2021$

Available online: May $27^{\text {th }}, 2021$

\section{Pendahulluan}

Ilmu kedokteran merupakan bidang keilmuan yang selalu mengalami perkembangan dari waktu ke waktu. Selain mengalami perkembangan dalam bidang keilmuan, masyarakat sebagai stakeholder dan juga konsumen dari jasa pelayanan kesehatan juga mengalami perubahan. Perubahan yang terjadi ini dipengaruhi oleh semakin tingginya pengetahuan dan pendidikan masyarakat serta malalui era globalisasi yang menyebabkan informasi semakin mudah diakses darimana dan kapan saja, hal ini secara tidak langsung mengubah perilaku masyarakat terhadap kesehatan dan pelayanan kesehatan. Beberapa hal tersebut yang menyebabkan masyarakat menginginkan dokter yang bukan hanya unggul dalam bidang keilmuan, namun juga dokter yang unggul dalam hal keterampilan dan juga dapat memberikan rasa aman serta nyaman dalam memberikan pelayanan kesehatan. ${ }^{1}$ Dengan demikian metode pembelajaran dalam pendidikan kedokteran juga perlu mengalami perkembangan dan perubahan untuk menciptakan proses belajar mengajar bagi profesi kesehatan sesuai dengan kebutuhan mahasiswa, dosen, dan juga masyarakat. ${ }^{2}$ karena itu maka di Indonesia terjadi pergeseran paradigma pendidikan kedokteran yang awalnya dengan teacher centered learning (TCL) mengarah ke student centered learning (SCL) karena dirasakan lebih sesuai dengan perubahan yang terjadi.

Sebagai respon terhadap perubahan ini maka sejak tahun 2004 Fakultas Kedokteran (FK) Universitas Andalas (UNAND) mulai menerapkan sistem belajar baru yaitu dengan sistem student centered learning (SCL) melalui pendekatan problem based learning atau biasa disingkat PBL. Penerapan sistem baru dalam pendidikan kedokteran di Universitas Andalas ini sesuai dengan kurikulum yang dikenalkan oleh konsil kedokteran Indonesia yaitu kurikulum berbasis kompetensi dengan pendekatan SPICES (student centered, problem based, integrated, community based, elective, sistematic). ${ }^{3}$ Dalam sistem PBL ini mahasiswa diajarkan untuk berpikir kritis dan juga menimbulkan keinginan mahasiswa untuk mencari serta mempelajari suatu pengetahuan berdasarkan kasus atau masalah yang

dimunculkan dalam sebuah skenario.

Sistem Student centered learning (SCL) dengan pendekatan problem based learning (PBL) yang diterapkan di FK UNAND ini sangat berbeda dengan sistem belajar yang digunakan oleh mahasiswa baru di jenjang pendidikan sebelumnya. Sistem pembelajaran yang umumnya diterapkan di Indonesia sejak Sekolah Dasar (SD) hingga Sekolah Menengah Atas (SMA)/Madrasah aliyah (MA) adalah sistem belajar teacher centered learning (TCL) atau biasa disebut sistem konvensional, dimana ilmu ditransfer dari guru ke murid melalui pembelajaran di kelas. Perbedaan inilah yang akan memaksa mahasiswa baru harus beradaptasi dengan sistem PBL yang jauh berbeda dengan sistem konvensional selama masa SMA/MA karena sistem PBL ini menerapkan andragogi (konsep pendidikan untuk orang dewasa). Kondisi seperti ini menyebabkan besar kemungkinan mahasiswa baru yang masuk ke FK UNAND akan mengalami culture shock termasuk dalam hal cara belajar sebelum dapat beradaptasi dengan sistem belajar baru. Dalam sebuah penelitian yang dilakukan Zuni di Universitas Tribhuwana Tunggadewi Malang pada tahun 2017 didapatkan hasil bahwa rata-rata mahasiswa mengalami kondisi culture shock sebesar $60 \%{ }^{4}$

Culture shock yang dialami oleh mahasiswa baru yang masuk ke dalam FK UNAND dapat merupakan salah satu penyebab stres yang dialami oleh mahasiswa. Dalam sebuah penelitian yang dilakukan oleh Kulsoom dan Afsal menggunakan instrumen depression, anxiety, and stress score (DASS) di Saudi Arabia pada tahun 2015 didapatkan hasil prevalensi stres pada mahasiswa kedokteran adalah sebesar $41,00 \%{ }^{5}$ Pada penelitian lain yang dilakukan oleh Dika et al. pada Mahasiswa Fakultas Kedokteran Universitas Hang Tuah Surabaya pada tahun 2010 didapatkan hasil mahasiswa kedokteran mengalami stres akibat penyesuaian diri terhadap tuntutan akademik adalah 16,2\%.6 Penelitian yang dilakukan oleh Rizkia pada tahun 2019 di Fakultas Kedokteran Universitas Andalas menggunakan kuesioner Medical Student Stressor Questionnaire didapatkan hasil mahasiswa tahun pertama 51,6\% mengalami stres berat terkait akademik dan $42 \%$ 
mengalami stres sedang akibat hubungan belajarmengajar. ${ }^{7}$

Untuk menghadapi culture shock yang menyebabkan stres maka mahasiswa baru memerlukan kemampuan untuk beradaptasi. Kemampuan adaptasi ini menurut penelitian yang dilakukan oleh Zuni pada tahun 2017 di Universitas Tribhuwana Tunggadewi Malang didapatkan hasil kemampuan adaptasi mahasiswa baru adalah sebesar 51\%.4 Dengan demikian dapat dikatakan bahwa mahasiswa tahun pertama yang baru memasuki FK UNAND akan mengalami berbagai masalah yang dapat diakibatkan karena belum dapat beradaptasi sepenuhnya dengan lingkungan maupun dengan cara belajar yang digunakan untuk kuliah. Permasalahan ini selanjutnya akan menyebabkan tidak optimalnya belajar pada $s$ tahun pertama karena masih mencari pola dan cara belajar yang baik serta sesuai untuk sistem belajar dengan pendekatan PBL ini.

Dalam sistem PBL, tutorial merupakan jantung dari PBL. Tutorial sendiri merupakan kegiatan diskusi yang dilakukan mahasiswa untuk membangkitkan rasa ingin tahu dan minat mahasiswa dalam suatu topik. Ada beberapa hal yang mempengaruhi tutorial seperti kemampuan berpikir kritis mahasiswa dan kemampuan mahasiswa untuk menganalisa suatu masalah. Tutorial hari pertama akan mengahasilkan tujuan pembelajaran atau biasa disebut dengan learning objective yang selanjutnya masing-masing mahasiswa pelajari lebih dalam melalui belajar mandiri mereka. Tutorial hari kedua mahasiswa akan melakukan sharing terhadap apa yang telah mereka dapatkan dalam belajar mandiri, seberapa banyak yang dapat dibagikan dengan yang lain pada tutorial hari kedua ini dipengaruhi oleh minat mahasiswa dalam suatu topik dan juga sangat dipengaruhi oleh kemampuan belajar mandiri (self directed learning) mahasiswa yang menjadi dasar untuk tercapainya indikatorindikator yang perlu dicapai mahasiswa sesuai dengan kompetensinya. Oleh karena itu dengan kualitas dan kuantitas belajar mandiri yang jelek maka kualitas tutorial juga akan menurun dan hal ini menyebabkan sistem PBL tidak berjalan dengan lancar dan tidak sesuai dengan harapan.

Masalah adaptasi yang dialami oleh mahasiswa baru ini dapat mempengaruhi dari kualitas dari belajar mandiri mahasiswa baru. Bagi mahasiswa yang telah melewati masa adaptasi itu dan juga telah mengenal dan mempraktekkan PBL dengan cara tutorial serta telah melakukan belajar mandiri, masa adaptasi ini sudah berhasil mereka lewati, maka dari itu mahasiswa tahun kedua, ketiga dan keempat FK UNAND yang telah melewati satu tahun lebih belajar dengan cara PBL ini akan memiliki kesiapan belajar mandiri/self directed learning readiness yang lebih baik. Selain pengalaman self directed learning readiness juga dipengaruhi oleh beberapa faktor, baik faktor internal maupun faktor eksternal, yaitu jenis kelamin, usia, cara belajar, mood dan kesehatan, pendidikan, intelegensi, motivasi belajar, waktu belajar, tempat belajar dan pola asuh orang tua. ${ }^{8}$

Kesiapan belajar mandiri mahasiswa kedokteran dalam penelitian yang dilakukan oleh Nyambe di Fakultas Kedokteran Hasanuddin pada tahun 2016 didapatkan hasil bahwa di antara mahasiswa tahun pertama, kedua dan ketiga nilai rata-rata SDLR paling rendah adalah mahasiswa tahun pertama yaitu 132,52 dengan range 102177 sedangkan nilai rata-rata SDLR yang paling tinggi dimiliki oleh mahasiswa tahun kedua yaitu 140,22 dengan range 86-180, sedangkan tahun ketiga memiliki rata-rata SDLR yang lebih tinggi dari tahun pertama namun lebih rendah dari tahun kedua yaitu 138,13 dengan range 95-174. ${ }^{9}$

Berdasarkan penelitian yang dilakukan oleh Oktadoni pada tahun 2015 yang dilakukan di Fakultas Kedokteran Universitas Lampung, kesiapan belajar mandiri/self directed learning readiness memiliki korelasi positif dengan nilai $\mathrm{p}=0,003$ terhadap prestasi belajar. Hal ini berarti semakin tinggi skor SDLR yang dimiliki oleh mahasiswa maka semakin baik prestasi belajar yang akan diperoleh oleh mahasiswa. ${ }^{10}$

Berdasarkan data-data di atas, peneliti tertarik melakukan penelitian untuk mengetahui gambaran Self Directed Learning Readiness mahasiswa program studi kedokteran Fakultas Kedokteran Universitas Andalas

\section{Metode}

Penelitian ini merupakan penelitian deskriptif dengan pendekatan cross sectional untuk mengetahui self directed learning readiness mahasiswa program studi kedokteran Fakultas Kedokteran Universitas Andalas. Penelitian ini dilaksanakan dari bulan Juni 2019-Juli 2020 di 
Fakultas Kedokteran Universitas Andalas, Padang, Sumatera Barat.

Populasi penelitian ini adalah semua mahasiswa program studi kedokteran Fakultas Kedokteran Universitas Andalas. Sampel penelitian yang dipilih adalah mahasiswa program studi kedokteran Fakultas Kedokteran Universitas Andalas yang memenuhi kriteria inklusi dan tidak memiliki kriteria eksklusi. Kriteria inklusi subjek: bersedia menjadi responden. Kriteria eksklusi subjek: Tidak mengisi kuesioner dengan lengkap;merupakan mahasiswa FK Unand yang berasal dari luar negri.

Data diperoleh dengan cara pengisian kuesioner oleh responden. Kuesioner yang digunakan adalah kuesioner SDLRS yang telah diadaptasi oleh Zulherman et al. Dengan butir pertanyaan sebanyak 36 buah dan telah dilakukan validasi oleh Nyambe dengan nilai uji validitas $(\mathrm{r}>0,268)$ dan reliabilitas (cronbach alpha=0,90). ${ }^{9,11}$

Teknik pengambilan sampel pada penelitian ini dilakukan dengan menggunakan metode stratified random sampling,dengan sampel minimal angkatan 2016 adalah 68 orang, sampel angkatan 2017 adalah 73 orang, sampel angkatan 2018 adalah 71 orang dan jumlah sampel untuk angkatan 2019 adalah 73 orang.

Data dianalisis secara statistic menggunakan sistem komputerisasi yaitu analisis univariat untuk melihat distribusi frekuensi variabel. Penelitian ini telah lulus kaji etik dengan nomor surat: 083/KEP/FK/2020 yang dikeluarkan oleh Komite Etik Penelitian Fakultas Kedokteran Universitas Andalas.

\section{Hasil}

Penelitian ini dilaksanakan di Fakultas Kedokteran Universitas Andalas terhadap mahasiswa program studi kedokteran angkatan 2016, 2017, 2018 dan 2019. Pengambilan data penelitian dilaksanakan pada Minggu pertama blok x.5. Populasi penelitian ini berjumlah 985 orang, yang kemudian diberikan kuesioner SDLR kepada 100 mahasiswa masing-masing angkatan. Dari kuesioner yang disebar didapatkan 72 mahasiswa angkatan 2016, 75 mahasiswa angkatan 2017. 80 mahasiswa angkatan 2018 dan 74 mahasiswa 2019 yang memenuhi kriteria inklusif dan kriteria eksklusi. Jumlah sampel penelitian ini sudah memenuhi jumlah sampel minimal yaitu 68 orang untuk 2016, 73 orang untuk 2017, 72 orang untuk 2018 dan 73 orang untuk 2019.

\section{Karakteristik responden}

Tabel 1. Distribusi Frekuensi Karakteristik Responden Berdasarkan Jenis Kelamin

\begin{tabular}{cllll}
\hline \multirow{2}{*}{ Angkatan } & \multicolumn{2}{l}{ Laki-laki } & \multicolumn{2}{c}{ Perempuan } \\
\cline { 2 - 5 } & f & $\mathbf{\%}$ & f & \% \\
\hline 2016 & $\mathbf{1 9}$ & $\mathbf{2 6 , 4}$ & $\mathbf{5 3}$ & $\mathbf{7 3 , 6}$ \\
2017 & $\mathbf{1 7}$ & $\mathbf{2 2 , 7}$ & $\mathbf{5 8}$ & $\mathbf{7 7 , 3}$ \\
2018 & $\mathbf{3 2}$ & $\mathbf{4 0}$ & $\mathbf{4 8}$ & $\mathbf{6 0}$ \\
2019 & $\mathbf{2 0}$ & $\mathbf{2 7}$ & $\mathbf{5 4}$ & $\mathbf{7 3}$ \\
\hline Total & $\mathbf{8 8}$ & $\mathbf{2 9 , 2}$ & $\mathbf{2 1 3}$ & $\mathbf{7 0 , 8}$ \\
\hline
\end{tabular}

Berdasarkan tabel 1 menunjukkan bahwa dari 301 responden yang menjadi sampel penelitian ini 88 orang berjenis kelamin laki-laki dan 213 orang berjenis kelamin perempuan. Hal tersebut menunjukkan bahwa sebagian besar sampel penelitian ini memiliki jenis kelamin perempuan yang dipersentasikan sebesar 70,8\%.

\section{Gambaran Tingkat Self Directed Learning Readiness Mahasiswa Program Studi Kedokteran}

Tabel 2. Distribusi Frekuensi dan Deskripsi Self Directed Learning Readiness

\begin{tabular}{lcccc}
\hline \multirow{2}{*}{ Kategori } & \multicolumn{4}{c}{ Angkatan } \\
\cline { 2 - 5 } & 2016 & 2017 & 2018 & 2019 \\
\hline SDLR & & & & \\
Tinggi & & & & 57 \\
$\quad$ f & 55 & 54 & 55 & 57 \\
$\quad \%$ & 76,4 & 72 & 68,8 & 77 \\
Sedang- & & & & \\
rendah & & & & \\
$\quad$ f & 17 & 21 & 5 & 17 \\
$\quad \%$ & 23,6 & 28 & 31,3 & 23 \\
Rata-rata & 140,31 & 136,8 & 138,48 & 137,97 \\
SD & 18,34 & 11,53 & 17 & 15,09 \\
Min & 45 & 107 & 65 & 79 \\
maks & 177 & 162 & 172 & 178 \\
\hline
\end{tabular}

Mahasiswa program studi kedokteran Fakultas Kedokteran Universitas Andalas tergolong memiliki kesiapan belajar mandiri tinggi karena sebanyak $221(73,4 \%)$ mahasiswa memiliki skor SDLR tinggi dan sebanyak $80(26,6 \%)$ mahasiswa memiliki skor SDLR sedang-rendah. Rata-rata skor SDLR mahasiswa program studi kedokteran Fakultas Kedokteran Universitas Andalas adalah 138,36 dengan skor minimal 45 dan skor maksimal 178 dan standar deviasi 15,67. 


\section{Gambaran Dimensi Sub Item Pertanyaan Self Directed Learning Readiness}

Tabel 3. Distribusi Frekuensi Dimensi Sub Item Self Directed Learning Readiness

\begin{tabular}{lllll}
\hline & \multicolumn{4}{c}{ Angkatan } \\
\cline { 2 - 5 } Dimensi & $\mathbf{2 0 1 6}$ & $\mathbf{2 0 1 7}$ & $\mathbf{2 0 1 8}$ & $\mathbf{2 0 1 9}$ \\
\cline { 2 - 5 } & Mean & Mean & Mean & Mean \\
& \pm SD & \pm SD & \pm SD & \pm SD \\
\hline Manajemen & $\mathbf{4 4 , 8 6}$ & $\mathbf{4 4 , 1 1}$ & $\mathbf{4 5 , 7 3}$ & $\mathbf{4 5 , 0 7}$ \\
Diri & $\pm 6,44$ & $\pm 4,63$ & $\pm 6,37$ & $\pm 4,97$ \\
Motivasi & $\mathbf{4 1}$ & 39,69 & 39,33 & 39,69 \\
Belajar & $\pm 5,31$ & $\pm 3,43$ & $\pm 5,3$ & $\pm 5,01$ \\
Kontrol Diri & $\mathbf{5 1 , 1 0}$ & 49,45 & 49,73 & 49,61 \\
& $\pm 7,25$ & $\pm 4,68$ & $\pm 6,3$ & $\pm 5,68$ \\
\hline
\end{tabular}

Berdasarkan data dalam tabel 3 didapatkan hasil, pada mahasiswa 2016, 2017, 2018 dan 2019 memiliki rata-rata yang hampir sama untuk masing-masing dimensi sub Item pertanyaannya.

\section{Pembahasan}

Dari penelitian ini diperoleh hasil secara keseluruhan mahasiswa program studi kedokteran Fakultas Kedokteran Universitas Andalas memiliki skor SDLR yang baik yang dapat dilihat pada tabel 2 yang menunjukkan sebanyak 221 (73,4\%) mahasiswa memiliki skor SDLR tinggi dan sebanyak 80 (26,6\%) mahasiswa memiliki skor SDLR sedang-rendah dengan ratarata 138,36 . Untuk dimensi sub item pertanyaan sdilihat pada tabel 3 didapatkan hasil pada masing-masing angkatan untuk dimensi sub item pertanyaan yang memiliki rata-rata tertinggi adalah kontrol diri kemudian manajemen diri dan rata-rata yang terendah adalah motivasi belajar. hasil ini berbeda dengan penelitian yang dilakukan oleh Naglaa pada tahun 2017 di King Abdulaziz University, Saudi Arabia menggunakan kuesioner SDLRS Fisher dengan skala likert 1-3 yang mendapatkan hasil tertinggi pada sub item pertanyaan kontrol diri dengan rata-rata dan standar deviasi 39,4 $\pm 4,8$; kemudian pada sub item motivasi belajar dengan rata-rata dan standar deviasi 30,8 $\pm 3,6$; dan yang terendah adalah sub item pertanyaan manajemen diri dengan rata-rata dan standar deviasi 30,5 $\pm 4,2.12$

Jika ditinjau untuk tiap angkatan, dari penelitian ini didapatkan hasil pada mahasiswa angkatan 2016 sebanyak 55 (76,4\%) mahasiswa memiliki skor SDLR tinggi, 17 (23,6\%) mahasiswa memiliki skor SDLR sedang-rendah. Rata-rata skor SDLR mahasiswa angkatan 2016 adalah
140,31 dengan skor terendah adalah 45 dan skor tertinggi adalah 177. Rata-rata skor SDLR mahasiswa 2016 adalah yang tertinggi dari angkatan lainnya, tetapi terdapat jarak yang lebar antara skor tertinggi dengan skor terendah yang menunjukkan bahwa angkatan 2016 masih ada mahasiswa dengan SDLR yang rendah. Tingginya rata-rata skor SDLR angkatan 2016 jika dilihat pada sub item pertanyaan, mahasiswa angkatan 2016 memiliki rata-rata dan standar deviasi tinggi pada motivasi belajar yaitu $41 \pm 5,31$ dan kontrol diri $51,10 \pm 7,25$. Hasil ini berbeda dengan hasil yang diperoleh Deyona dalam penelitiannya yang dilakukan di Universitas Sebelas Maret pada tahun 2014 yang mendapatkan hasil rata-rata SDLR mahasiswa tahun 4 147,41 (76-197) yang lebih rendah dari rata-rata skor SDLR mahasiswa tahun pertama 149,09 (104-200).13 Hasil penelitian ini sesuai dengan teori yang dikemukakan oleh Leach pada tahun 2000 yang menyebutkan bahwa individu yang memiliki pengalaman lebih banyak akan memiliki skor SDLR yang lebih tinggi. ${ }^{14}$

Hasil penelitian pada mahasiswa angkatan 2017 adalah 54 (72\%) mahasiswa memiliki skor SDLR tinggi, 21 (28\%) mahasiswa memiliki skor SDLR sedang-rendah. Rata-rata skor SDLR mahasiswa angkatan 2017 adalah 136,8 dengan skor terendah 107 dan skor tertinggi 162. Ratarata skor SDLR pada mahasiswa angkatan 2017 merupakan yang terendah dari angkatan lain. Hal ini sejalan dengan hasil penelitian yang dilakukan oleh Nyambe di Fakultas Kedokteran Universitas Hasanuddin pada tahun 2016 dengan hasil mahasiswa tahun ketiga memiliki skor SDLR terendah dengan rata-rata 138,13 (95-175) dibandingkan dengan mahasiswa tahun pertama dengan rata-rata skor SDLR 132,52 (102-177) dan mahasiswa tahun kedua dengan rata-rata skor SDLR 140,22 (86-180). ${ }^{9}$

Rendahnya skor SDLR angkatan 2017 dilihat dari dimensi sub item pertanyaan disebabkan karena memiliki rata-rata dan standar deviasi rendah pada manajemen diri yaitu $44,11 \pm 4,63$ dan kontrol diri 49,45 $\pm 4,68$. Manajemen diri dipengaruhi oleh kemampuan mahasiswa mengamati diri, mengevaluasi diri, dan hal ini dipengaruhi oleh dukungan lingkungan untuk memberikan penguatan terhadap hasil. ${ }^{15}$ Kontrol diri masing-masing mahasiswa dipengaruhi oleh faktor orang tua dan teman sebaya. ${ }^{9}$ Hal ini yang menyebabkan terdapat perbedaan kontrol diri 
untuk masing-masing mahasiswa. Pada tahun ajaran 2018/2019 mahasiswa angkatan 2017 juga mengalami pindah kampus, yang awalnya kampus FK Unand berpusat di Jati dipindahkan ke Limau Manis. Menurut Gunanegara beberapa faktor yang mempengaruhi penerapan Self Directed Learning seperti, lingkungan pembelajaran yang kurang kondusif, terlalu padatnya jadwal, dan kurang tersedianya fasilitas seperti perpustakaan dan juga internet. ${ }^{16}$ Saat terjadi perpindahan lokasi kampus tidak semua pembelajaran dilakukan di Limau Manis, tetapi beberapa kegiatan masih dilaksanakan di Jati, hal ini menyebabkan jadwal kosong digunakan mahasiswa untuk berpindah lokasi sehingga jadwal terasa terlalu padat dan lingkungan pembelajaran kurang kondusif. Selain itu fasilitas perpustakaan FK Unand di Limau Manis belum selengkap kampus di Jati, beberapa hal ini dapat menjadi penyebab rendahnya ratarata skor SDLR angkatan 2017.

Pada mahasiswa angkatan 201855 (68,8\%) mahasiswa memiliki skor SDLR tinggi, 25 (31,3\%) mahasiswa dengan skor SDLR sedang-rendah. Rata-rata skor SDLR pada mahasiswa angkatan 2018 adalah 138,48 dengan skor terendah 65 dan skor tertinggi 172 . Hasil ini sejalan dengan penelitian yang dilakukan oleh Nyambe di Fakultas Kedokteran Universitas Hasanuddin pada tahun 2016 yaitu mahasiswa tahun kedua memiliki rata-rata skor SDLR yang lebih tinggi dari mahasiswa tahun pertama. ${ }^{9}$ dilihat dari dimensi sub item pertanyaan, angkatan 2018 memiliki rata-rata dan standar deviasi tinggi pada manajemen diri yaitu 45,73 $\pm 6,37$ dan rendah pada motivasi belajar yaitu $39,33 \pm 5,3$. Motivasi belajar mahasiswa dipengaruhi oleh beberapa hal, seperti : Cita-cita, Mood dan kesehatan, Keadaan lingkungan, Kondisi pendidik dan Kondisi individu. ${ }^{17}$

Mahasiswa 2019 pada penelitian ini memperoleh hasil 57 (77\%) mahasiswa dengan skor SDLR tinggi, 17 (23\%) mahasiswa dengan skor SDLR sedang-rendah dengan rata-rata skor SDLR 137,97 skor terendah 79 dan skor tertinggi 178. Skor SDLR mahasiswa angkatan 2019 memiiki rata-rata cukup rendah hal ini disebabkan karena masih kurangnya pengalaman melaksanakan belajar mandiri angkatan 2019 dibandingkan dengan angkatan lainnya, rendahnya skor angkatan 2019 sesuai dengan teori Leach pada tahun 2000 yang menyatakan bahwa skor SDLR sejalan dengan jumlah pengalaman melaksanakan belajar mandiri seseorang. ${ }^{14}$ Pada dimensi sub item pertanyaan motivasi belajar, manajemen diri dan kontrol diri mahasiswa angkatan 2019 tidak ada yang menonjol.

Masih ditemukan mahasiswa dengan skor SDLR sedang-rendah berkaitan dengan faktorfaktor internal dan eksternal yang menyebabkan perbedaan skor SDLR masing-masing individu berbeda. Beberapa faktor eksternal yang bekaitan dengan SDLR menurut Aruan dalam penelitiannya pada tahun 2013 di UIN Syarif Hidayatullah antara lain, tahun masuk Universitas, asal sekolah dan sumber bacaan mahasiswa. ${ }^{18}$

Mahasiswa yang berasal dari sekolah yang telah mengimplementasikan SCL atau belajar mandiri seperti kurikulum 2013 memiliki pengalaman lebih banyak dalam melaksanakan belajar mandiri, hal inilah yang menjadi faktor penyebab memiliki skor SDLR yang lebih tinggi. Sumber bacaan mahasiswa erat kaitannya dengan fasilitas, dan semakin lengkap fasilitas maka skor SDLR semakin meningkat. ${ }^{18}$ faktor eksternal lain yang mempengaruhi belajar mandiri adalah waktu belajar. Waktu belajar merupakan bagian dari hal yang perlu direncanakan mahasiswa dalam melaksanakan belajar mandiri. Kemampuan mahasiswa dalam memanajemen waktu dapat menyebabkan terlaksananya pembelajaran secara mandiri dengan baik. ${ }^{19}$

Faktor internal lain yang mempengaruhi SDLR adalah cara belajar. Menurut Dalyono, cara belajar adalah metode untuk mencapai sebuah keberhasilan dalam sebuah pembelajaran. ${ }^{20}$ Kemudian faktor lain yang mempengaruhi SDLR adalah Mood dan kesehatan mahasiswa, mahasiswa yang memiliki Mood dan kesehatan baik mempengaruhi mahasiswa untuk melaksanakan belajar secara mandiri. ${ }^{21}$

\section{Simpulan}

Berdasarkan hasil penelitian ini didapatkan kesimpulan bahwa self directed learning readiness pada mahasiswa pendidikan dokter Fakultas Kedokteran Universitas Andalas angkatan 2016, 2017, 2018, 2019 dalam kategori baik. Angkatan dengan skor SDLR tertinggi adalah angkatan 2016, sedangkan angkatan dengan skor SDLR terendah adalah angkatan 2017. 
Tingginya rata-rata skor SDLR angkatan 2016 sesuai dengan tingginya motivasi dan kontrol dirinya. Untuk angkatan 2017 memiliki rata-rata skor SDLR rendah juga sesuai dengan rendahnya manajemen diri dan kontrol diri, sedangkan untuk 2018 memiliki manajemen diri yang baik tetapi rendah dalam motivasi belajar. Angkatan 2019 berada dalam rentang tengah antara manajemen diri, motivasi belajar dan kontrol diri.

\section{Ucapan Terima Kasih}

Terima kasih penulis sampaikan kepada semua pihak yang telah membantu dalam pelaksanaan dan penyelesaian penilitian ini.

\section{Daftar Pustaka}

1. Muhamad Faizal. Kesiapan hukum menghadapi globalisasi pelayanan kesehatan di Indonesia. Jendela Huk dan Keadilan. 2016;3:1-17.

2. Cohen RJ, Swerdlik ME, Phillips SM. Psychological testing and assessment. 6th ed. Swerdlik M, editor. New York: Mc Graw Hill Companies; 2005.

3. ISKDI. Standar Kompetensi Dokter Indonesia Konsil Kedokteran Indonesia [Internet]. 2012. Available from:

http://www.kki.go.id/assets/data/arsip/SKDI_Perk onsil,_11_maret_13.pdf

4. Mitasari, et A. Studi pola penyesuaian diri mahasiswa luar jawa di universitas tribhuwana tunggadewi malang. Semin Nas dan Gelar Prod. 2017;(0341):796-803.

5. Kulsoom B, Afsar NA. Stress, anxiety, and depression among medical students in a multiethnic setting. Neuropsychiatr Dis Treat. 2015;11:1713-22.

6. Christyanti D, Mustami'ah D, Sulistiani W. Hubungan antara Penyesuaian Diri terhadap Tuntutan Akademik dengan Kecenderungan Stres pada Mahasiswa Fakultas Kedokteran Universitas Hang Tuah Surabaya. Insan. 2010;12(03):153-9.

7. Rahmayani RD, Liza RG, Syah NA. Gambaran Tingkat Stres Berdasarkan Stressor pada Mahasiswa Kedokteran Tahun Pertama Program Studi Profesi Dokter Fakultas Kedokteran Universitas Andalas Angkatan 2017. J Kesehat Andalas. 2019;8(1):103.

8. Ramli N, Muljono P, Afendi FM. Faktor-Faktor yang berpengaruh terhadap self directed learning readiness dan prestasi akademik. J Kependidikan. 2018;2(1):153-66.

9. Nyambe H, Rahayu GR, Kedokteran J, Kedokteran F, Hasanuddin U, Kedokteran DP, et al. Faktor-Faktor yang Mempengaruhi Self Directed Learning Readiness pada Mahasiswa Tahun Pertama, Kedua, dan Ketiga di Fakultas Kedokteran Universitas Hasanuddin dalam PBL. J Pendidik Kedokt Indones Indones J Med Educ. 2016;5(2):67-77.

10. Saputra O, Lisiswanti R, Aftria MP. Korelasi SelfDirected Learning Readiness (SDLR) Terhadap Prestasi Belajar Mahasiswa Tahun Pertama Fakultas Kedokteran Universitas Lampung TahunAjaran 2014/2015. In: Prosiding Seminar Presentasi Artikel Ilmiah Dies Natalis FK Unila ke-13 Lampung: FK Unila. 2015.

11. Zulharman H, Kumara A. Peran self directed learning readiness pada prestasi belajar mahasiswa tahun pertama Fakultas Kedokteran Universitas Riau. J Pendidik Kedokt dan Profesi Kesehat Indones. 2008;3(3):104-8.

12. El Seesy N, Sofar SM, Al-Battawi JAI. Self-directed learning readiness among nursing students at King Abdulaziz University, Saudi Arabia. IOSR J Nurs Heal Sci. 2017;6(6):14-24.

13. Putri DA. Perbedaan self directed learning readiness pada mahasiswa pendidikan dokter fk uns semester I dan semester vii. 2015;

14. Leach LJ. Self-directed learning: Theory and practice. 2000.

15. Adicondro N, Purnamasari A. Efikasi diri, dukungan sosial keluarga dan self regulated learning pada siswa kelas VIII. Universitas Ahmad Dahlan; 2011.

16. Gunanegara RF, Wahid MH, Widyahening IS. Comparison of Studentsâ€TM Characteristics, SelfMotivation, and Readiness of Self-Directed Learning Implementation among Medical Students at Maranatha Christian University. J Med Heal. 2017;1(5).

17. Dimyati M. Belajar \& Pembelajaran. Jakarta: Rineka Cipta. 2013;

18. Aruan N. Gambaran Kesiapan Self Directed Learning Pada Mahasiswa Tahap Pendidikan Klinik UIN Syarif Hidayatulah Dan Faktor--Faktor Yang Berhubungan. 2013;

19. Ertug N, Faydali S. Investigating the relationship between self-directed learning readiness and time management skills in Turkish undergraduate nursing students. Nurs Educ Perspect. 2018;39(2):E2--E5.

20. Dewi IA, others. Hubungan kecerdasan emosional dengan kesiapan belajar mandiri mahasiswa di Fakultas Kedokteran Universitas Lampung. 2019;

21. Sugianto IM, Lisiswanti R. Tingkat self directed learning readiness (SDLR) pada mahasiswa kedokteran. J Major. 2016;5(5):27-31. 